\title{
Impact of Medical Marijuana Legalization on Opioid Use, Chronic Opioid Use, and High-risk Opioid Use
}

\author{
Anuj Shah, $P h D^{7}$, Corey J. Hayes, PharmD, $M P H^{2,3}$, Mrinmayee Lakkad, $\mathrm{MS}^{2}$, and Bradley C. Martin, \\ PharmD, $P h D^{2}$
}

\begin{abstract}
${ }^{1}$ Pharmerit International, Bethesda, MD, USA; ${ }^{2}$ Division of Pharmaceutical Evaluation and Policy, Department of Pharmacy Practice, College of Pharmacy, University of Arkansas for Medical Sciences, Little Rock, AR, USA; ${ }^{3}$ Division of Health Services Research, Psychiatric Research Institute, College of Medicine, University of Arkansas for Medical Sciences, Little Rock, AR, USA.
\end{abstract}

OBJECTIVE: To determine the association of medical marijuana legalization with prescription opioid utilization.

METHODS: A 10\% sample of a nationally representative database of commercially insured population was used to gather information on opioid use, chronic opioid use, and high-risk opioid use for the years 2006-2014. Adults with pharmacy and medical benefits for the entire calendar year were included in the population for that year. Multilevel logistic regression analysis, controlling for patient, person-year, and state-level factors, were used to determine the impact of medical marijuana legalization on the three opioid use measures. Sub-group analysis among cancer-free adults and cancer-free adults with at least one chronic non-cancer pain condition in the particular year were conducted. Alternate regression models were used to test the robustness of our results including a fixed effects model, an alternate definition for start date for medical marijuana legalization, a person-level analysis, and a falsification test.

RESULTS: The final sample included a total of 4,840,562 persons translating into $15,705,562$ person years. Medical marijuana legalization was found to be associated with a lower odds of any opioid use: OR=0.95 (0.94-0.96), chronic opioid use: $\mathrm{OR}=0.93$ (0.91-0.95), and high-risk opioid use: $\mathrm{OR}=0.96$ (0.94-0.98). The findings were similar in both the sub-group analyses and all the sensitivity analyses. The falsification tests showed no association between medical marijuana legalization and prescriptions for antihyperlipidemics (OR = 1.00; CI 0.99-1.01) or antihypertensives (OR=1.00; CI 0.99-1.01).

CONCLUSIONS: In states where marijuana is available through medical channels, a modestly lower rate of opioid and high-risk opioid prescribing was observed. Policy makers could consider medical marijuana legalization as a tool that may modestly reduce chronic and high-risk opioid use. However, further research assessing risk versus benefits of medical marijuana legalization and head to head comparisons of marijuana versus opioids for pain management is required.

Electronic supplementary material The online version of this article (https://doi.org/10.1007/s11606-018-4782-2) contains supplementary material, which is available to authorized users.

Received April 3, 2018

Revised September 11, 2018

Accepted November 27, 2018

Published online January 25, 2019
KEY WORDS: opioids; marijuana; chronic opioid use; medical marijuana legalization; pain.

J Gen Intern Med 34(8):1419-26

DOI: $10.1007 / \mathrm{s} 11606-018-4782-2$

(C) Society of General Internal Medicine 2019

\section{INTRODUCTION}

Despite substantial documentation of risks associated with long-term opioid use and the lack of evidence on long-term opioid therapy for chronic pain management ${ }^{1}$, opioids are one of the most commonly prescribed drugs in the USA. ${ }^{2}$ Although the rates of opioid prescribing have declined since 2010, they still remain approximately 3 times higher than rates in $1999 .^{3}$ In $2016,66.5$ opioid prescriptions per 100 persons were dispensed. ${ }^{4}$ Over $25 \%$ of drug overdose deaths occurring in 2017 involved the use of a prescription opioid, and deaths related to prescription opioid overdose have increased by over $400 \%$ from 2000 to $2017 . .^{5}$ The rise in opioid use, misuse, and overdose has led to opioid prescribing becoming a topic of national importance. President Trump has declared opioid misuse as a National Public Health Emergency ${ }^{6}$ and state and national governments are taking active measures to curb opioid prescribing. ${ }^{7}$

Although marijuana is a federall schedule $1 \mathrm{drug}$, since 1996, 30 states and DC have legalized marijuana for medical uses, and since 2013, 9 states have legalized its recreational use. ${ }^{8}$ In states where marijuana is legalized for medical use, chronic pain is one of the approved indications ${ }^{9}$ and a majority of persons acquiring medical marijuana do so for pain management. ${ }^{10}$ Medical marijuana patients report a higher likelihood of substituting or reducing opioid use while managing their pain with medical marijuana. ${ }^{11-14}$ Today, fewer people perceive marijuana to be harmful compared to a decade ago. ${ }^{15}$ The perceived safety of marijuana coupled with its legalization for chronic pain management could lead to an overall decline in opioid use. However, studies show a high prevalence of concomitant use of cannabis and opioids among pain patients. ${ }^{16,17}$ Furthermore, marijuana has been hypothesized to be a "gateway drug," suggesting that increased cannabis availability, through legalization, may increase use of other drugs such as opioids. ${ }^{18,19}$ 
Currently, mixed evidence exists concerning the effects of medical marijuana legalization (MML) on opioid use and opioid-related outcomes. Studies have shown fewer opioid overdose deaths, ${ }^{20,}{ }^{21}$ decreases in admissions for opioid addiction, ${ }^{21,22}$ and reductions in hospitalizations for opioid overdoses $^{22}$ following medical marijuana legalization. Medical marijuana legalization was also found to be associated with an overall decrease in analgesic prescriptions among elderly Medicare patients. ${ }^{23}$ However, medical marijuana legalization was not associated with opioid misuse ${ }^{24}$ or the number of opioids distributed to retail and medical settings in a state. ${ }^{21}$ To the best of our knowledge, no previous studies have explored the association between medical marijuana legalization and the likelihood of acute and chronic prescription opioid utilization.

The variability in states' decisions to legalize marijuana creates a natural experiment to determine whether medical marijuana legalization is associated with opioid use. This study aims to determine the association between states' decisions to legalize medical marijuana and the likelihood of opioid use, chronic opioid use, and high-risk opioid use.

\section{METHODS}

\section{Data Sources}

We used a random $10 \%$ sample of patients from the IMS Lifelink+ database from 2006 to 2014. IMS Lifelink+ is a nationally representative database of commercially insured patients and includes their enrollment information and inpatient, outpatient, and insurance-funded pharmacy claims. The demographic variables in the person-level enrollment file include age, sex, state of residence, and type of payer (Medicare, Medicaid, commercial insurance, etc.). The inpatient and outpatient files contain diagnosis information, procedure codes, and the date of service for all insurance claims filed for an enrollee from 2006 to 2014. The pharmacy file includes retail as well as mail order prescription records from 2006 to 2014 .

The Area Health Resource File was used to gather statelevel data on unemployment rates and the number of physicians per 1000 residents for each study year (2006-2014). It is a publically available dataset which gathers data from multiple sources. ${ }^{25}$ It has socioeconomic data and data on availability and type of healthcare professionals and health facilities.

The National Alliance for Model State Drug Laws (NAMSDL), which comprises information on state policies concerning alcohol and drug regulation, was used to gather information on states' implementation of Prescription Drug Monitoring Programs and Pain Clinic Laws. ${ }^{26}$

\section{Study Subjects}

For each year, the study population comprised of all persons aged $\geq 18$ on January 1 st of that particular year. The subjects were also required to have pharmacy and medical benefits for the entire year. Persons with missing or invalid age, gender, state of residence, and payer information in the respective year were excluded for that year. We restricted the sample to adults because medical marijuana is exclusively legalized for adult consumption. Because a subject could meet these criteria in multiple years, each observation represented a person year and not a unique patient.

\section{Study Outcomes}

Opioid Use: At least one opioid prescription in the year was defined as opioid use for that year.

Chronic Opioid Use: At least 90 days of opioid use, with a gap of no greater than 30 days between consecutive opioid prescriptions, within a 180-day period, in a calendar year, was defined as chronic opioid use for that year. This definition of chronic opioid use was derived from previously published studies. $^{27-29}$

High-Risk Opioid Use: Opioid use along with at least one of the following: (a) At least 1 day of overlap between opioid and benzodiazepine prescription (b) A maximum daily dose for opioids being $\geq 120$ morphine milligram equivalents (MME) (c) A substance use disorder diagnosis in the same year as an opioid prescription was defined as high-risk opioid use.

Proprietary Generic Product Identifier codes were used to identify claims for opioids and benzodiazepines, and diagnosis codes to identify substance use disorder are provided in Supplementary Table 1.

\section{Independent Variable}

The main independent variable was an indicator of whether medical marijuana law was in effect for each state in each particular year between 2006 and 2014. In the years prior to being effective, it was coded as zero and years after becoming effective it was coded as 1 , and the year when it became effective it was coded as the fraction of the year in which the law became effective. The start dates for MML in each state, defined as the date when the statute legalizing medical marijuana became effective, were obtained from previous literature and publically available data (Supplementary Table 2.). ${ }^{21,30}$

\section{Covariates}

Individual- and state-level factors that could influence the likelihood of opioid use were included as covariates. Individual-level demographics factors (gender, payertype, date of birth, and state of residence) were obtained from the enrollment file. These demographics remained constant for each observation of the same patient. Conditions that might influence the likelihood of opioid use in that particular year were obtained from the medical claims. The conditions determined were based on a previously published study ${ }^{28}$ and included chronic non-cancer pain 
(joint pain, back or neck pain, neuropathic pain, headache fibromyalgia), non-chronic pain (abdominal pain, chest pain, other pain), cancer, childbirth, dental visit, trauma, surgery, inpatient admissions for conditions other than those mentioned earlier, and emergency room visit for conditions other than those mentioned earlier. If a patient was included in the sample for more than 1 year, they might have separate conditions in each year depending on their medical claims for that year. The diagnosis and procedure codes to identify each of these conditions are provided in the Supplementary Table 1. State-level factors included the presence of a prescription monitoring program, whether pain clinic laws were in effect, the rate of physicians per 1000 residents, and the proportion of unemployed residents.

\section{Analysis}

Frequency counts and proportions of the patient-level characteristics were calculated for the following three mutually exclusive groups: states that never legalized medical marijuana on or before 2014, pre-MML for states which passed the legislation from 2006 to 2014, and post MML for states which legalized medical marijuana any time in or before 2014. The frequency counts represent patient years, not unique patients. The distributions for each of the characteristics were compared between the three groups using chi-square tests. Means and standard deviations were calculated for the two state-level characteristics, rate of physicians, and proportion unemployed and comparisons between the three groups were made using one-way ANOVA.

To determine the effect of MML on opioid utilization measures, two-level, multivariate hierarchical logistic regression models were estimated. Hierarchical models allowed us to account for clustering of individual patients within states, but due to large number of enrollees in our final sample and computational limitations of software, we were unable to account for clustering of multiple observations within the same person. The state of residence was incorporated as a random effect. Study year, patient-year-level characteristics and state-level characteristics were all incorporated in the models as fixed effects. Mean predicted probability of opioid use, chronic opioid use, and high-risk opioid use was calculated for MML vs no MML states.

\section{Sub-group Analysis}

To determine the impact of MML on opioid utilization among non-cancer pain patients, we conducted a sub-group analysis by excluding all observations for persons with a cancer diagnosis (except non-melanoma skin cancer) in any year from 2006 to 2014 .

In another sub-group analysis, we estimated the effect of MML on opioid utilization among chronic non-cancer pain patients. We restricted the sample to cancer-free adults which had at least one diagnosis for a chronic non-cancer pain condition in the particular year.

\section{Sensitivitiy Analysis}

To account for the delay between effective date and the actual availability of medical marijuana, a sensitivity analysis was conducted where the start date of MML was considered to be the date when the first dispensary commenced operations for states that prohibit cultivation by patients or designated caregivers and use dispensaries to distribute marijuana (Supplementary Table 2). Next, models where the state of residence and year were specified as fixed effects were used to model each outcome. Third, because of our inability to account for nesting of multiple observations within an individual, we conducted a person-level analysis by including only the first observation for each patient that met the inclusion/exclusion criteria. Lastly, a falsification test was conducted that explored the impact of MML on the likelihood of antihyperlipidemic and antihypertensive drug use. The falsification test was conducted to determine whether our findings might be explained by residual confounding and a null finding for these outcomes would refute, though not disprove, that residual confounding is responsible for any observed differences in our opioid outcomes.

\section{RESULTS}

A total of $4,973,963$ persons translating to $16,153,580$ person years met the inclusion criteria of which 133,401 (2.68\%) persons and 448,018 (2.77\%) person years had missing/ invalid age, gender, payer, or state information and were excluded. The final sample comprised of $4,840,562$ persons translating into $15,705,562$ person years. The sample predominantly consisted of persons with commercial or self-paid insurance, between the ages of 31 and 54 years of age and approximately $35 \%$ had a chronic pain diagnosis (Table 1 ). In states that legalized marijuana, post MML, the sample was slightly older, more likely to be male, and have more chronic non-cancer pain diagnoses compared to pre-legalization (Table 1). In states which never legalized marijuana during or before 2014, the population was younger, less likely to have chronic non-cancer pain diagnoses, or non-chronic pain diagnoses compared to states which legalized marijuana on or before 2014 (Table 1).

States that did not legalize marijuana prior to December 2014 had a higher proportion of opioid use, chronic opioid use, and high-risk opioid use than states that did enact MML in unadjusted analyses (Table 1.).

In the fully adjusted analyses, MML was associated with a lower probability of opioid use (MML: $19.290 \%$ No MML:19.900\%; Diff (95\% CI):0.604 (0.591-0.618); OR $(95 \%$ CI $)=0.95(0.94-0.96))$, chronic opioid use (MML:1.750\% No MML:1.870\%; Diff (95\% CI):0.118\% $(0.116 \%-0.120 \%)$; OR $(95 \% \mathrm{CI})=0.93(0.91-0.95))$ and high-risk opioid use (MML:2.600\% No MML:2.500\%; Diff (95\% CI): $0.093 \%(0.090 \%-0.096 \%)$; OR $(95 \% \mathrm{CI})=0.96$ (0.94-0.98)) (Tables 2 and 4.). The results were similar among 
Table 1 Patient- and State-Level Characteristics in States That Never Legalized Medical Marijuana and Pre- and Post Legalization in States That Legalized Medical Marijuana

\begin{tabular}{|c|c|c|c|}
\hline \multirow[t]{2}{*}{ Characteristics } & \multicolumn{2}{|c|}{ States that legalized medical marijuana* } & \multirow{2}{*}{$\begin{array}{l}\text { States that did not legalize } \\
\text { medical marijuana prior to } 2014^{\dagger} \\
(N=8,951,128 ; 56.99 \%)\end{array}$} \\
\hline & $\begin{array}{l}\text { Pre MML } \\
(N=3,784,947 ; 24.10 \%)\end{array}$ & $\begin{array}{l}\text { Post MML } \\
(N=2,969,487 ; 18.91 \%)\end{array}$ & \\
\hline \multirow{2}{*}{\multicolumn{4}{|c|}{ Patient-level characteristics }} \\
\hline & \multicolumn{3}{|c|}{$\mathrm{Age}^{*}$} \\
\hline $18-21$ & $270,473(7.15 \%)$ & $211,620(7.13 \%)$ & $628,459(7.02 \%)$ \\
\hline $22-30$ & $481,659(12.73 \%)$ & $373,167(12.57 \%)$ & $1,203,777(13.45 \%)$ \\
\hline $55-65$ & $793,109(20.95 \%)$ & $622,583(20.97 \%)$ & $1,924,692(21.50 \%)$ \\
\hline $65+$ & $363,381(9.60 \%)$ & $370,350(12.47 \%)$ & $630,613(7.05 \%)$ \\
\hline Females & $2,007,843(53.05 \%)$ & $1,536,625(51.75 \%)$ & $4,572,313(51.08 \%)$ \\
\hline \multicolumn{4}{|l|}{ Payer type } \\
\hline Commercial & $2,532,620(66.91 \%)$ & $2,026,216(68.23 \%)$ & $5,983,519(66.85 \%)$ \\
\hline Self-pay & $1,060,019(28.01 \%)$ & $792,287(26.68 \%)$ & $2,920,990(32.63 \%)$ \\
\hline Medicaid & $53,057(1.40 \%)$ & $28,184(0.95 \%)$ & $5751(0.06 \%)$ \\
\hline Childbirth & $42,313(1.12 \%)$ & $31,617(1.06 \%)$ & $96,022(1.07 \%)$ \\
\hline Trauma & $607,032(16.04 \%)$ & $515,109(17.35 \%)$ & $1,260,762(14.08 \%)$ \\
\hline Surgery & $310,398(8.20 \%)$ & $246,305(8.29 \%)$ & $741,977(8.29 \%)$ \\
\hline Burn & $8315(0.22 \%)$ & $6285(0.21 \%)$ & $18,931(0.21 \%)$ \\
\hline Non-chronic pain diagnosis & $1,380,701(36.48 \%)$ & $1,074,221(36.18 \%)$ & $3,204,447(35.30 \%)$ \\
\hline Opioid use t $^{\ddagger}$ & $710,338(18.77 \%)$ & $582,794(19.63 \%)$ & $1,889,495(21.11 \%)$ \\
\hline High-risk opioid use & $82,150(2.17 \%)$ & $72,954(2.54 \%)$ & $276,995(3.09 \%)$ \\
\hline Chronic opioid use & $62,223(1.64 \%)$ & $65,130(2.19 \%)$ & $205,597(2.30 \%)$ \\
\hline \multicolumn{4}{|l|}{ State-level characteristics } \\
\hline Number of state years & 76 & 131 & 243 \\
\hline Percent unemployed ${ }^{*}$ & $5.07(1.25)$ & $5.28(1.49)$ & $4.69(1.36)$ \\
\hline Number of physicians per 1000 persons $\ddagger$ & $3.34(0.73)$ & $2.87(0.68)$ & $2.37(0.47)$ \\
\hline
\end{tabular}

Unit of observation for patient level characteristics is person years, and they are expressed as frequency and \% of person years, and compared between the three groups using chi-square tests. Unit of observation for state-level characteristics is state years, and they are expressed as mean and standard deviations, and compared between the three groups using analysis of variance. If MML was effective before or in the month of July of the respective year, then the data for the entire year was described in the post-MML group, whereas if MML was effective after July of the respective year, then the data was described in the pre-MML group

*Pre-MML group comprises of data prior to medical marijuana legalization in the 12 states that legalized medical marijuana in our study period (20062014): AZ, CT, DE, IL, MA, MD, MI, MN, NH, NJ, NM, and NY. Post-MML group comprises of data after medical marijuana legalization in the 12 states that legalized medical marijuana in the study period as well as data from the states that legalized medical marijuana prior to 2006: AK, CA, CO, HI, ME, MT, NV, OR, RI, VT, and WA. (RI's MML was effective from January 1st 2006, so was considered as having MML throughout the study period) ${ }^{\dagger}$ States that never legalized medical marijuana comprises of data from states did not legalize medical marijuana any time before December 2014: AL, $A R, F L, G A, I A, I D, I N, K S, K Y, L A, M O, M S, N D, N C, N E, O H, O K, P A, S C, S D, T N, T X, U T, V A, W I$, WV, and WY ${ }^{t} p<0.05$

non-cancer patients (opioid use: MML: $16.650 \%$ no MML: $17.340 \%$; Diff (95\% CI):0.692\% (0.676\%-0.707\%); OR (95\% CI):0.94 (0.93-0.95); chronic opioid use: MML:1.600\% no MML:1.720\%; Diff (95\% CI):0.117\% $(0.115 \%-0.119 \%)$; OR (95\% CI):0.93 (0.90-0.96); HighRisk Opioid Use: MML:2.130\% No MML:2.230\%; Diff (95\% CI):0.107\% (0.104\%-0.110\%); OR (95\% CI):0.95 $(0.92-0.97))$ as well as among chronic non-cancer pain patients (opioid use: MML:33.490\% no MML:34.710\%; Diff (95\% CI): $1.230 \%(1.200 \%-1.260 \%)$; OR (95\% CI):0.94 (0.92-0.95); chronic opioid use: MML:4.540\% no MML:4.820\%; Diff (95\% CI):0.279\% (0.275\%-0.284\%); OR (95\% CI):0.94 (0.91-0.97); high-risk opioid use: MML:5.120\% no MML:5.550\%; Diff (95\% CI):0.431\% (0.423\%-0.440\%); OR (95\% CI):0.91 (0.88-0.94)).

The results after using the alternative model specifications, modifying the definition of the start date of MML, and including only one observation per-person were consistent with our primary analysis (Tables 3 and 4). The falsification test revealed that, as anticipated, MML had no impact on the utilization of antihyperlipidemic or antihypertensive drugs (Table 2).

\section{DISCUSSION}

Medical marijuana legalization was associated with lower odds of opioid use, chronic opioid use, and high-risk opioid use when controlling for many state-level and patient-level factors. Similar results were observed even after excluding cancer patients, restricting to cancer-free adults with at least one chronic non-cancer pain diagnosis, changing the regression modeling technique, or conducting a person-level analysis. In addition, the falsification test demonstrating that MML 
Table 2 Odds Ratios of Impact of Medical Marijuana Legalization on Opioid Use, Chronic Opioid Use, and High-risk Opioid and Antidiabetic and Antihypertensive Drug Use

\begin{tabular}{|c|c|c|c|}
\hline \multirow[t]{2}{*}{ Outcome } & \multirow{2}{*}{$\frac{\text { Full population }}{\text { Odds ratio }(95 \% \mathrm{CI})}$} & \multirow{2}{*}{$\frac{\text { Non-cancer patients }}{\text { Odds ratio }(95 \% \mathrm{CI})}$} & \multirow{2}{*}{$\begin{array}{l}\text { Chronic non-cancer pain patients } \\
\text { Odds ratio }(95 \% \mathrm{CI})\end{array}$} \\
\hline & & & \\
\hline Opioid use* & $0.95(0.94-0.96)$ & $0.94(0.93-0.95)$ & $0.94(0.92-0.95)$ \\
\hline Chronic opioid use* & $0.93(0.91-0.95)$ & $0.93(0.90-0.96)$ & $0.94(0.91-0.97)$ \\
\hline High-risk opioid use* & 0.96 & 0.95 & 0.91 \\
\hline Antihyperlipidemic prescriptions & $\begin{array}{l}(0.94-0.98) \\
1.00 \\
(0.99-1.01)\end{array}$ & $\begin{array}{l}(0.92-0.97) \\
-\end{array}$ & $\begin{array}{l}(0.88-0.94) \\
-\end{array}$ \\
\hline Antihypertensive Prescriptions & $\begin{array}{l}1.00 \\
(0.99-1.01)\end{array}$ & - & - \\
\hline
\end{tabular}

A multilevel logistic regression model with state of residence as random effects and year as fixed effect was used

*In addition to state of residence and year, the models accounted for patient age, gender and payer type, whether the patients received a chronic pain diagnosis, non-chronic pain diagnosis or experienced trauma, surgery, childbirth, dental procedure, any inpatient stay, burn or any emergency department visit in the given year. Also the model accounted for the following state level factors as fixed effects: presence of prescription drug monitoring program, presence of pain clinic laws, unemployment rate and number of physicians per 1000 persons

status had no impact on any of the use of antihyperlipdemics or antihypertensives adds confidence to these findings suggesting that residual confounding is less likely. This study indicates that legalizing medical marijuana is associated with lower use of opioids and opioids used chronically across states, broadly, and in subgroups of cancer patients and cancer-free groups with chronic pain.

The impact of MML on chronic opioid use is noteworthy considering that chronic opioid use, more so than acute opioid use, is positively associated with opioid misuse. ${ }^{31}$ Chronic opioid use is also shown to be associated with greater medical $\operatorname{costs}^{32}$ and, in many cases, leads to dose escalation due to developing tolerance, and eventually opioid overdoses. ${ }^{33} \mathrm{We}$ also found a small but significant association between medical marijuana legalization and the lower likelihood of high-risk opioid use, which we defined as having overlapping prescription of benzodiazepines and opioids, high-dose opioid prescriptions (>120 MME), or an opioid prescription with a history of substance use disorder. In a survey among patients on chronic opioid therapy, nearly a third of patients reported concomitantly using benzodiazepines, ${ }^{34}$ and simultaneous use of this drug class has been shown to increase the likelihood of respiratory depression and fatality. ${ }^{35}$ Prescribing opioids to persons with a history of substance use disorders is also associated with a greater likelihood of long-term opioid use $^{28}$ and higher-dose opioid prescriptions are associated with a greater likelihood of unintentional opioid overdoses. ${ }^{36}$ In light of these facts, the negative association between MML and chronic opioid use, and high-risk opioid prescribing, though modest, may lead to lower rates of unintended consequences of prescription opioid use.

While this study highlights that making marijuana legally available may mitigate the use of opioids, it does not offer any insights as to the efficacy of marijuana in pain management. Although the pharmacologic properties of opioids and marijuana differ substantially, they both share a potential for misuse and medical marijuana legalization is shown to increase the likelihood of illicit use of marijuana as well. ${ }^{37}$ Furthermore, marijuana use may also be associated with developing substance use disorders for other substances including alcohol, tobacco, and illicit drugs. ${ }^{38}$ Marijuana use is also found to be associated with impairment in certain cognitive domains, ${ }^{38-40}$ an increased likelihood of adverse pulmonary function after prolonged exposure ${ }^{38,41}$ and development of psychotic symp-

Table 3 Sensitivity Analysis of Impact of Medical Marijuana Legalization on Opioid Use, Chronic Opioid Use, and High-risk Opioid

\begin{tabular}{|c|c|c|c|}
\hline \multirow[t]{2}{*}{ Outcome } & \multirow{2}{*}{$\frac{\text { Sensitivity analysis I* }}{\text { Odds ratio }(95 \% \mathrm{CI})}$} & \multirow{2}{*}{ 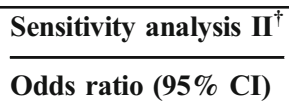 } & \multirow{2}{*}{$\begin{array}{l}\text { Sensitivity analysis III } \\
\text { Odds ratio }(95 \% \mathrm{CI})\end{array}$} \\
\hline & & & \\
\hline $\begin{array}{l}\text { Opioid use }^{\S} \\
\text { Chronic opioid use } \\
\text { High-risk opioid use }\end{array}$ & $\begin{array}{l}0.95(0.94-0.96) \\
0.96(0.93-0.98) \\
0.95(0.93-0.98)\end{array}$ & $\begin{array}{l}0.94(0.93-0.95) \\
0.93(0.91-0.95) \\
0.96(0.93-0.98)\end{array}$ & $\begin{array}{l}0.90(0.89-0.92) \\
0.83(0.80-0.87) \\
0.90(0.86-0.93)\end{array}$ \\
\hline
\end{tabular}

*Sensitivity analysis I used the availability of dispensaries to define the start date of MML in states which prohibited cultivation by patients or their primary caregivers

${ }^{{ }^{\prime}}$ Sensitivity analysis II was a logistic regression model with both state of residence and year specified as fixed effects and standard errors clustered within state to account for nesting of patients within a state

${ }^{7}$ Sensitivity analysis III included only the first observation for each patient such that each patient was used in the analysis only once

SIn addition to state of residence and year, the models accounted for patient age, gender and payer type, whether the patients received a chronic pain diagnosis, non-chronic pain diagnosis or experienced trauma, surgery, childbirth, dental procedure, any inpatient stay, burn, or any emergency department visit in the given year. Also the model accounted for the following state level factors as fixed effects: presence of prescription drug monitoring program, presence of pain clinic laws, unemployment rate and number of physicians per 1000 persons 
Table 4 Percentage Predicted Probability of Opioid Use, Chronic Opioid Use, and High-risk Opioid in MML and No MML States

\begin{tabular}{|c|c|c|c|c|c|c|c|c|c|}
\hline \multirow[t]{2}{*}{ Outcome } & \multicolumn{3}{|c|}{ Opioid use* } & \multicolumn{3}{|c|}{ Chronic opioid use* } & \multicolumn{3}{|c|}{ High-risk opioid use* } \\
\hline & $\begin{array}{l}\text { MML } \\
\text { states }\end{array}$ & $\begin{array}{l}\text { No MML } \\
\text { states }\end{array}$ & $\begin{array}{l}\text { Diff } \\
(95 \% \text { CI })\end{array}$ & $\begin{array}{l}\text { MML } \\
\text { states }\end{array}$ & $\begin{array}{l}\text { No MML } \\
\text { states }\end{array}$ & $\begin{array}{l}\text { Diff } \\
(95 \% \text { CI })\end{array}$ & $\begin{array}{l}\text { MML } \\
\text { states }\end{array}$ & $\begin{array}{l}\text { No MML } \\
\text { states }\end{array}$ & $\begin{array}{l}\text { Diff } \\
(95 \% \mathrm{CI})\end{array}$ \\
\hline \multicolumn{10}{|l|}{ Primary analysis ${ }^{\dagger}$} \\
\hline \multicolumn{10}{|l|}{ Population } \\
\hline $\begin{array}{l}\text { Full } \\
\text { population }\end{array}$ & 19.290 & 19.900 & $\begin{array}{l}0.604 \\
(0.591-0.618)\end{array}$ & 1.750 & 1.870 & $\begin{array}{l}0.118 \\
(0.116-0.12)\end{array}$ & 2.600 & 2.500 & \multirow{3}{*}{$\begin{array}{l}0.093 \\
(0.090-0.096) \\
0.107 \\
(0.104-0.11) \\
0.431 \\
(0.423-0.44)\end{array}$} \\
\hline $\begin{array}{l}\text { Non-cancer } \\
\text { patients }\end{array}$ & 16.650 & 17.340 & $\begin{array}{l}0.692 \\
(0.676-0.707)\end{array}$ & 1.600 & 1.720 & $\begin{array}{l}0.117 \\
(0.115-0.119)\end{array}$ & 2.130 & 2.230 & \\
\hline $\begin{array}{l}\text { Chronic non- } \\
\text { cancer pain } \\
\text { patients }\end{array}$ & 33.490 & 34.710 & $\begin{array}{l}1.230 \\
(1.200-1.260)\end{array}$ & 4.540 & 4.820 & $\begin{array}{l}0.279 \\
(0.275-0.284)\end{array}$ & 5.120 & 5.550 & \\
\hline \multicolumn{10}{|l|}{ Sensitivity analysis } \\
\hline $\begin{array}{l}\text { Sensitivity } \\
\text { analysis } I^{*}\end{array}$ & 17.710 & 18.290 & $\begin{array}{l}0.577 \\
(0.564-0.591)\end{array}$ & 1.730 & 1.870 & $\begin{array}{l}0.135 \\
(0.133-0.137)\end{array}$ & 2.340 & 2.440 & \multirow{3}{*}{$\begin{array}{l}0.103 \\
(0.100-0.106) \\
0.104 \\
(0.101-0.107) \\
0.211 \\
(0.205-0.216)\end{array}$} \\
\hline $\begin{array}{l}\text { Sensitivity } \\
\text { analysis } I^{\S}\end{array}$ & 18.120 & 18.790 & $\begin{array}{l}0.674 \\
(0.660-0.688)\end{array}$ & 1.880 & 2.000 & $\begin{array}{l}0.122 \\
(0.120-0.125)\end{array}$ & 2.470 & 2.570 & \\
\hline $\begin{array}{l}\text { Sensitivity } \\
\text { analysis III" }\end{array}$ & 18.490 & 19.680 & $\begin{array}{l}1.190 \\
(1.160-1.210)\end{array}$ & 1.560 & 1.860 & $\begin{array}{l}0.294 \\
(0.290-0.297)\end{array}$ & 2.070 & 2.280 & \\
\hline
\end{tabular}

Predicted probabilities were estimated from each model and multiplied by 100 to obtain percentage predicted probability. Differences were calculated using $t$ tests.

*In addition to state of residence and year, the models accounted for patient age, gender, and payer type, whether the patients received a chronic pain diagnosis, non-chronic pain diagnosis or experienced trauma, surgery, childbirth, dental procedure, any inpatient stay, burn, or any emergency department visit in the given year. Also the model accounted for the following state level factors as fixed effects: presence of prescription drug monitoring program, presence of pain clinic laws, unemployment rate, and number of physicians per 1000 persons

${ }^{\dagger}$ A multilevel logistic regression model with state of residence as random effects and year as fixed effect was used.

${ }^{*}$ Sensitivity analysis I used the availability of dispensaries to define the start date of MML in states which prohibited cultivation by patients or their primary caregivers

${ }^{\S}$ Sensitivity analysis II was a logistic regression model with both state of residence and year specified as fixed effects and standard errors clustered within state to account for nesting of patients within a state

"Sensitivity analysis III included only the first observation for each patient such that each patient was used in the analysis only once

toms. ${ }^{38,42-44}$ Most of the studies assessing the benefits and harms of marijuana are short term and none of the studies have carried out head-to-head comparisons between marijuana and opioids. This study emphasizes the need for more research to establish the risk-benefit profile for marijuana because these findings suggest that despite the lack of conclusive evidence on marijuana's long-term safety, it might be substituting opioids for acute and chronic pain management where available legally.

These findings need to be interpreted in light of the following limitations. First, prescriptions obtained by either paying out-of-pocket or obtained illicitly were not included in this study. However, this would only influence the findings if marijuana legalization would change the likelihood of patients seeking opioids through these sources. Second, the analyses do not control for the number of dispensaries or number of plants allowed in home cultivation within a state which could influence the level of medical marijuana penetration. Third, this study controlled for some opioid policies including prescription drug monitoring programs and pain clinics but did not control for others such as prescription limits, tamperresistant prescriptions, doctor-shopping restrictions, physician examination, and pharmacist verification. Although, a study evaluating the effects of these laws found no association between implementation of these laws and opioid use ${ }^{45}$. Fourth, we did not determine whether the reduction in chronic use was due to persons on chronic therapy discontinuing opioids or whether fewer patients who initiated opioids continued to use them chronically. Fifth, although we have data from 50 states, our data may not be representative of the commercially insured population at the state level. Sixth, we did not have data on the extent patients in our study were using medical cannabis, and hence, we can only speculate that reductions in opioid use associated with MML were because of a substitution effect. Lastly, when this study reports lower odds of opioid use in adjusted analyses, we are actually reporting a rate that is lower relative to states that did not implement MML pooled with pre-MML time periods in states that did implement MML. It should be noted that opioid use, chronic use, and high-risk opioid use increased, on average, in unadjusted analyses after implementation of MML.

\section{CONCLUSION}

These results suggest that MML could be one policy tool that may modestly decrease opioid use; chronic and highrisk opioid use in a landscape where pain management options are limited and opioid misuse and addiction are rising rapidly. However, more research on the health benefits of marijuana is required ${ }^{38,46}$ and future analyses weighing the potential benefits of decreased likelihood of opioid use with the potential risks of MML such as increased prevalence of mental health disorders and misuse of marijuana need to be conducted. ${ }^{37,38}$ 
Corresponding Author: Bradley C. Martin, PharmD, PhD; Division of Pharmaceutical Evaluation and Policy, Department of Pharmacy Practice, College of Pharmacy University of Arkansas for Medical Sciences, Little Rock, AR, USA (e-mail: bmartin@uams.edu).

Funder Data obtained for this project was supported by the Translational Research Institute (TRI), grant UL1TR000039. Dr. Hayes was supported by the Translational Training in Addiction [1T32 DA 022981].

\section{Compliance with Ethical Standards:}

Conflict of Interest: Dr. Anuj Shah was a graduate student at the University of Arkansas for Medical Sciences the entire duration of time this study was conducted. Dr. Shah is now an employee of Pharmerit International which is a contract research organization which receives revenue from pharmaceutical companies. None of the research presented in this manuscript is in any way associated with Dr.Shah's present employment. No conflict of interests exist for Dr. Corey Hayes. No conflict of interests exist for Miss Mrinmayee Lakkad. Bradley C. Martin receives royalties from TrestleTree, a healthcare coaching company, for the exclusive use of an opioid risk prediction tool that he and his colleagues developed.

Publisher's Note Springer Nature remains neutral with regard to jurisdictional claims in published maps and institutional affiliations.

\section{REFERENCES}

1. Chou R, Deyo R, Devine B, et al. The Effectiveness and Risks of LongTerm Opioid Treatment of Chronic Pain. 2014. https://doi.org/10. 23970/AHRQEPCERTA218.

2. Daubresse $\mathbf{M}$, Chang $\mathbf{H}-\mathbf{Y}, \mathbf{Y u} \mathbf{Y}$, et al. Ambulatory Diagnosis and Treatment of Nonmalignant Pain in the United States, 2000-2010. Med Care. 2013;51(10):870-878. https://doi.org/10.1097/MLR. Ob013e3182a95d86.

3. Guy GP Jr, Zhang K, Bohm MK, Losby J, Lewis B, Young R, Murphy LB, Dowell D. Vital Signs: Changes in Opioid Prescribing in the United States, 2006-2015. MMWR Morb Mortal Wkly Rep. 2017;66(26):697704. https://doi.org/10.15585/mmwr.mm6626a4.

4. Department of Health U, Services H, for Disease Control C. Annual surveillance report of drug-related risks and outcomes united states, 2017. https://www.cdc.gov/. Accessed October 19, 2018.

5. National Center for Health Statistics, CDC Wonder. Drug Involved in U.S Overdose Deaths, 1999-2017. 2018. https://www.drugabuse.gov/relat ed-topics/trends-statistics/overdose-death-rates. Accessed October 19, 2018.

6. Davis J. Trump Declares Opioid Crisis a 'Health Emergency' but Requests No Funds - The New York Times. The New York Times. https://www. nytimes.com/2017/10/26/us/politics/trump-opioid-crisis.html. Pub lished 2017. Accessed October 19, 2018.

7. Kelly, Erin Groppe M. House passing bills to fight opioid addiction. Usa Today. http://www.indystar.com/story/news/politics/2016/05/11/ house-passing-bills-fight-opioid-addiction/84250820/. Accessed October 19,2018

8. 31 Legal Medical Marijuana States and DC - Medical Marijuana - ProCon. org. https://medicalmarijuana.procon.org/view.resource.php?resourceID=000881. Accessed October 19, 2018.

9. Qualifying Conditions for Medical Marijuana by State | Leafly. https:// www.leafly.com/news/health/qualifying-conditions-for-medical-marijuana-by-state. Accessed October 19, 2018.

10. Bonn-Miller MO, Boden MT, Bucossi MM, Babson KA. Self-reported cannabis use characteristics, patterns and helpfulness among medical cannabis users. Am J Drug Alcohol Abuse. 2014;40(1):23-30. https:// doi.org/10.3109/00952990.2013.821477.

11. Boehnke KF, Litinas E, Clauw DJ. Medical Cannabis Use Is Associated With Decreased Opiate Medication Use in a Retrospective Cross-Sectional Survey of Patients With Chronic Pain. J Pain. 2016;17(6):739-744 https://doi.org/10.1016/j.jpain.2016.03.002
12. Lucas P, Walsh Z. Medical cannabis access, use, and substitution for prescription opioids and other substances: A survey of authorized medical cannabis patients. Int J Drug Policy. 2017;42:30-35. https:// doi.org/10.1016/j.drugpo.2017.01.011.

13. Reiman A, Welty M, Solomon P. Cannabis as a Substitute for OpioidBased Pain Medication: Patient Self-Report. Cannabis Cannabinoid Res. 2017;2(1):160-166. https://doi.org/10.1089/can.2017.0012.

14. Corroon J, Mischley L, Sexton M. Cannabis as a substitute for prescription drugs - a cross-sectional study. J Pain Res. 2017;10:989998. https://doi.org/10.2147/JPR.S134330.

15. Okaneku J, Vearrier D, McKeever RG, LaSala GS, Greenberg MI. Change in perceived risk associated with marijuana use in the United States from 2002 to 2012. Clin Toxicol. 2015;53(3):151-155. https://doi. org/10.3109/15563650.2015.1004581.

16. Degenhardt $\mathbf{L}$, Lintzeris $\mathbf{N}$, Campbell G, et al. Experience of adjunctive cannabis use for chronic non-cancer pain: Findings from the Pain and Opioids IN Treatment (POINT) study. Drug Alcohol Depend. 2015;147:144-150. https://doi.org/10.1016/j.drugalcdep. 2014.11.031.

17. Reisfield GM, Wasan AD, Jamison RN. The Prevalence and Significance of Cannabis Use in Patients Prescribed Chronic Opioid Therapy: A Review of the Extant Literature. Pain Med. 2009;10(8):1434-1441. https://doi. org/10.1111/j.1526-4637.2009.00726.x.

18. Fergusson DM, Boden JM, Horwood LJ. Cannabis use and other illicit drug use: testing the cannabis gateway hypothesis. Addiction. 2006;101(4):556-569. https://doi.org/10.1111/j.1360-0443.2005. 01322.x.

19. Bostwick JM. Blurred boundaries: the therapeutics and politics of medical marijuana. Mayo Clin Proc. 2012;87(2):172-186. https://doi. org/10.1016/j.mayocp.2011.10.003.

20. Bachhuber MA, Saloner B, Cunningham CO, Barry CL. Medical Cannabis Laws and Opioid Analgesic Overdose Mortality in the United States, 1999-2010. JAMA Intern Med. 2014;174(10):1668. https://doi. org/10.1001/jamainternmed.2014.4005.

21. Powell D, Pacula RL, Jacobson M. Do Medical Marijuana Laws Reduce Addictions and Deaths Related to Pain Killers? Cambridge, MA; 2015. https://doi.org/10.3386/w21345.

22. Shi Y. Medical marijuana policies and hospitalizations related to marijuana and opioid pain reliever. Drug Alcohol Depend. 2017;173:144-150. https://doi.org/10.1016/j.drugalcdep.2017.01. 006.

23. Bradford AC, Bradford WD. Medical Marijuana Laws Reduce Prescription Medication Use In Medicare Part D. Health Aff (Millwood). 2016;35(7):1230-1236. https://doi.org/10.1377/hlthaff.2015.1661.

24. Wen H, Hockenberry JM, Cummings JR. The effect of medical marijuana laws on adolescent and adult use of marijuana, alcohol, and other substances. J Health Econ. 2015;42:64-80. https://doi.org/10. 1016/j.jhealeco.2015.03.007.

25. HRSA Data Warehouse - Area Health Resource Files. https://datawarehouse.hrsa.gov/topics/ahrf.aspx. Accessed October 19, 2018.

26. The National Alliance for Model State Drug Laws (NAMSDL). http://www. namsdl.org/. Accessed October 19, 2018.

27. Shah A, Hayes CJ, Martin BC. Characteristics of Initial Prescription Episodes and Likelihood of Long-Term Opioid Use - United States, 2006-2015. MMWR Morb Mortal Wkly Rep. 2017;66(10):265-269. https://doi.org/10.15585/mmwr.mm6610a1.

28. Shah A, Hayes CJ, Martin BC. Factors Influencing Long-Term Opioid Use Among Opioid Naive Patients: An Examination of Initial Prescription Characteristics and Pain Etiologies. J Pain. 2017;18(11):1374-1383. https://doi.org/10.1016/j.jpain.2017.06.010.

29. Martin BC, Fan M-Y, Edlund MJ, Devries A, Braden JB, Sullivan MD. Long-term chronic opioid therapy discontinuation rates from the TROUP study. J Gen Intern Med. 2011;26(12):1450-1457. https://doi.org/10. 1007/s11606-011-1771-0.

30. 31 Legal Medical Marijuana States and DC - Medical Marijuana - ProCon. org. http://medicalmarijuana.procon.org/view.resource.php?resourceID=000881. Accessed October 19, 2018.

31. Sullivan MD, Edlund MJ, Fan MY, Devries A, Brennan Braden J, Martin BC. Risks for possible and probable opioid misuse among recipients of chronic opioid therapy in commercial and medicaid insurance plans: The TROUP Study. Pain. 2010;150(2):332-339. https://doi.org/10.1016/j.pain.2010.05.020[doi].

32. Leider HL, Dhaliwal J, Davis EJ, Kulakodlu M, Buikema AR. Healthcare costs and nonadherence among chronic opioid users. Am J Manag Care. 2011;17(1):32-40. http://www.ncbi.nlm.nih.gov/pubmed/ 21348566. Accessed October 19, 2018. 
33. Longo DL, Volkow ND, McLellan AT. Opioid Abuse in Chronic Pain Misconceptions and Mitigation Strategies. N Engl J Med. 2016;374(13):1253-1263. https://doi.org/10.1056/NEJMra1507771.

34. Saunders KW, Von Korff M, Campbell CI, et al. Concurrent use of alcohol and sedatives among persons prescribed chronic opioid therapy: prevalence and risk factors. J Pain. 2012;13(3):266-275. https://doi.org/ 10.1016/j.jpain.2011.11.004.

35. Jones JD, Mogali S, Comer SD. Polydrug abuse: a review of opioid and benzodiazepine combination use. Drug Alcohol Depend. 2012;125(12):8-18. https://doi.org/10.1016/j.drugalcdep.2012.07.004[doi].

36. Bohnert ASB, Valenstein M, Bair MJ, et al. Association Between Opioid Prescribing Patterns and Opioid Overdose-Related Deaths. JAMA. 2011;305(13):1315. https://doi.org/10.1001/jama.2011.370.

37. Hasin DS, Sarvet AL, Cerdá M, et al. US Adult Illicit Cannabis Use, Cannabis Use Disorder, and Medical Marijuana Laws. JAMA Psychiatry. 2017;74(6):579. https://doi.org/10.1001/jamapsychiatry.2017.0724.

38. National Academies of Sciences and Medicine E. The Health Effects of Cannabis and Cannabinoids: The Current State of Evidence and Recommendations for Research. National Academies Press; 2017.

39. Ganzer F, Bröning S, Kraft S, Sack P-M, Thomasius R. Weighing the Evidence: A Systematic Review on Long-Term Neurocognitive Effects of Cannabis Use in Abstinent Adolescents and Adults. Neuropsychol Rev. 2016;26(2):186-222. https://doi.org/10.1007/s11065-016-9316-2.

40. Schreiner AM, Dunn ME. Residual effects of cannabis use on neurocognitive performance after prolonged abstinence: A meta-analysis. Exp
Clin Psychopharmacol. 2012;20(5):420-429. https://doi.org/10.1037/ a0029117.

41. Pletcher MJ, Vittinghoff E, Kalhan R, et al. Association Between Marijuana Exposure and Pulmonary Function Over 20 Years. JAMA. 2012;307(2): 173. https://doi.org/10.1001/jama.2011.1961.

42. Kuepper R, van Os $\mathbf{J}$, Lieb $\mathbf{R}$, Wittchen $\mathbf{H}-\mathbf{U}$, Höfler $\mathbf{M}$, Henquet $\mathbf{C}$. Continued cannabis use and risk of incidence and persistence of psychotic symptoms: 10 year follow-up cohort study. BMJ. 2011;342:d738. http://www.ncbi.nlm.nih.gov/pubmed/21363868. Accessed October 19, 2018.

43. Dominguez M-G, Saka MC, Lieb R, Wittchen H-U, van Os J, van Os J. Early Expression of Negative/Disorganized Symptoms Predicting Psychotic Experiences and Subsequent Clinical Psychosis: A 10-Year Study. Am J Psychiatry. 2010;167(9):1075-1082. https://doi.org/10.1176/ appi.ajp.2010.09060883

44. Moore TH, Zammit S, Lingford-Hughes A, et al. Cannabis use and risk of psychotic or affective mental health outcomes: a systematic review. Lancet. 2007;370(9584):319-328. https://doi.org/10.1016/S01406736(07)61162-3.

45. Meara E, Horwitz JR, Powell W, et al. State Legal Restrictions and Prescription-Opioid Use among Disabled Adults. N Engl J Med. 2016;375(1):44-53. https://doi.org/10.1056/NEJMsa1514387.

46. Hill KP. Medical Marijuana for Treatment of Chronic Pain and Other Medical and Psychiatric Problems: A Clinical Review. JAMA. 2015;313(24):2474-2483. https://doi.org/10.1001/jama.2015.6199. 